\title{
Modulation of Hyaluronan Synthesis by the Interaction between Mesenchymal Stem Cells and Osteoarthritic Chondrocytes
}

\author{
Eliane Antonioli, ${ }^{1}$ Carla A. Piccinato, ${ }^{1}$ Helena B. Nader, ${ }^{2}$ Moisés Cohen, ${ }^{3}$ \\ Anna Carla Goldberg, ${ }^{1}$ and Mario Ferretti ${ }^{1}$ \\ ${ }^{1}$ Hospital Israelita Albert Einstein, No. 627/701, 05652-900 São Paulo, SP, Brazil \\ ${ }^{2}$ Department of Biochemistry, Molecular Biology Program, Federal University of São Paulo, No. 100, 04044-020 São Paulo, SP, Brazil \\ ${ }^{3}$ Orthopedic Division, Federal University of São Paulo, No. 783, 04038-031 São Paulo, SP, Brazil \\ Correspondence should be addressed to Mario Ferretti; mario.ferretti@einstein.br
}

Received 13 November 2014; Revised 11 December 2014; Accepted 2 January 2015

Academic Editor: Mark F. Pittenger

Copyright (C) 2015 Eliane Antonioli et al. This is an open access article distributed under the Creative Commons Attribution License, which permits unrestricted use, distribution, and reproduction in any medium, provided the original work is properly cited.

\begin{abstract}
Bone marrow mesenchymal stem cells (BM-MSCs) are considered a good source for cellular therapy in cartilage repair. But, their potential to repair the extracellular matrix, in an osteoarthritic environment, is still controversial. In osteoarthritis (OA), anti-inflammatory action and extracellular matrix production are important steps for cartilage healing. This study examined the interaction of BM-MSC and OA-chondrocyte on the production of hyaluronan and inflammatory cytokines in a Transwell system. We compared cocultured BM-MSCs and OA-chondrocytes with the individually cultured controls (monocultures). There was a decrease in BM-MSCs cell count in coculture with OA-chondrocytes when compared to BM-MSCs alone. In monoculture, BM-MSCs produced higher amounts of hyaluronan than OA-chondrocytes and coculture of BM-MSCs with OA-chondrocytes increased hyaluronan production per cell. Hyaluronan synthase- 1 mRNA expression was upregulated in BM-MSCs after coculture with OA-chondrocytes, whereas hyaluronidase-1 was downregulated. After coculture, lower IL-6 levels were detected in BM-MSCs compared with OA-chondrocytes. These results indicate that, in response to coculture with OA-chondrocytes, BM-MSCs change their behavior by increasing production of hyaluronan and decreasing inflammatory cytokines. Our results indicate that BM-MSCs per se could be a potential tool for OA regenerative therapy, exerting short-term effects on the local microenvironment even when cell:cell contact is not occurring.
\end{abstract}

\section{Introduction}

Osteoarthritis (OA) is a pathology accompanied by an increased secretion of inflammatory cytokines and proteolytic molecules into the surrounding tissue, leading to extracellular matrix degeneration and functional impairment [1]. The capacity of adult chondrocytes to maintain cartilage homeostasis declines with age, with loss of the ability to secrete the extracellular matrix components responsible for the characteristic viscoelastic properties of the cartilage [2]. Hyaluronan and aggrecan act as the major aggregating factors for collagen, proteoglycans, and water, playing a key role in the maintenance of the cartilage structure and the ability to resist to compressive loads $[3,4]$.

Hyaluronan is a glycosaminoglycan composed of repeated disaccharide units synthesized by hyaluronan synthases
(HASs), which are membrane-bound enzymes. There are three isoforms in humans, HAS-1, HAS-2, and HAS-3, which produce hyaluronan molecules of different molecular sizes. HAS-1 and HAS-2 produce higher molecular weight hyaluronan molecules $\left(>2 \times 10^{6} \mathrm{Da}\right)[5,6]$. High molecular weight hyaluronan has been described as an anti-inflammatory and immunosuppressive molecule, whereas low hyaluronan fragments exhibit immunostimulatory and proinflammatory effects [7].

Degradation of hyaluronan is regulated by hyaluronidases. There are six hyaluronidase-like sequences in the human genome [7]; however, only three hyaluronidases (HYAL1, HYAL-2, and HYAL-3) have been described in cartilage [8]. Each enzyme acts upon molecules of different molecular weight paving the way for hyaluronan turnover in 
the cartilage. HYAL-1 degrades hyaluronan of all molecular weights to smaller oligomers. HYAL-2 cleaves only high and intermediate molecular weight hyaluronan yielding products of approximately $20 \mathrm{kDa}$, while little is known about HYAL-3 enzymatic activity $[7,9]$. Of the three hyaluronidase genes, HYAL-2 is the most expressed in normal chondrocytes. Currently, there are indications that in OA there are lower hyaluronan levels and with altered molecular weight and that hyaluronidases are upregulated in response to inflammatory cytokines [10-12].

Inflammation has been described as an important factor in the development and progression of OA. The main proinflammatory cytokines described in the pathophysiology of OA are interleukin- (IL-) 1 beta, TNF, IL-6, and also IL8 [13]. These cytokines contribute to the pathogenesis of OA through several mechanisms leading to a shift in chondrocytes phenotype. In an inflammatory environment chondrocytes become activated and increase further the expression of proinflammatory cytokines and factors involved in tissue catabolism, namely, matrix metalloproteinases and other proteolytic enzymes, which degrade hyaluronan, aggrecan, collagen, and fibromodulin. Such fragments of matrix components, in turn, also help maintain the production of inflammatory cytokines $[1,14]$. Alternative therapies for cartilage regeneration in OA should ideally reduce inflammation and promote tissue remodeling. In this context, the use of mesenchymal stem cells (MSCs) has been pointed out as an interesting therapeutic option [14, 15], due to their distinct immunomodulatory, anti-inflammatory, and regenerative properties [16, 17]. MSCs anti-inflammatory properties might also be able to change chondrocytes phenotype, decreasing production of inflammatory molecules and favoring the renewal of extracellular components.

Indeed, interaction between MSCs and chondrocytes has been studied in vitro, especially in the context of cartilage development, evidencing a role of MSCs in forming cartilage tissue [18-20]. However, the effects of MSCs on OAchondrocytes and on their capacity to repair the extracellular matrix have not yet been fully examined. Likewise, the potential effect of OA-chondrocytes on MSCs has so far been overlooked. In vitro coculture of MSCs and OAchondrocytes represents a powerful approach to distinguish the contribution of each cell type and their interaction. Using cells from the same patients, we proposed to investigate the effects caused by the interaction with no physical contact between MSCs and OA-chondrocytes on the secretion of inflammatory markers and on hyaluronan synthesis.

\section{Materials and Methods}

2.1. Culture and Isolation of Human Bone Marrow Stem Cell and Chondrocytes. Both OA-chondrocytes and BMMSCs were obtained from six patients undergoing total knee replacement (TKR) surgery. All patients were women (ages 63-80 years; average age: 70 years) with Grade III or IV knee OA according to the Kellgren and Lawrence classification [21]. Articular cartilage and bone marrow were harvested from the distal femur during TKR procedure. The study was carried out in full accordance with local ethical guidelines
(CEP/Einstein 10/1268 Hospital Israelita Albert Einstein; CAAE: 0006.0.028.000-10) and samples were collected after obtaining written informed consent from all donors.

For isolation of chondrocytes, slices of OA knee cartilage from each donor were separately incubated in $0.25 \%$ type I collagenase in Dulbecco's modified Eagle's medium (DMEM) (Sigma, St. Louis, MO), overnight at $37^{\circ} \mathrm{C}$ in $5 \% \mathrm{CO}_{2}$. The cells were then seeded onto tissue culture flasks for expansion and maintained as subconfluent monolayers in DMEM with low glucose (DMEM-LG) supplemented with $1 \mathrm{mM}$ of $L$-glutamine, $10 \%$ fetal bovine serum (FBS), and $1 \%$ antibiotic-antimycotic solution (Gibco/Life Technologies, Carlsbad, CA).

A small volume of bone marrow was drawn from the distal femur to obtain BM-MSCs [22] and diluted in equal volume of phosphate buffered saline (PBS). The cells were then layered over Ficoll (density, 1.03 to $1.12 \mathrm{~g} / \mathrm{mL}$; GE) and centrifuged at $500 \mathrm{~g}$ for 30 minutes. Mononuclear cells were collected, seeded onto tissue flasks, and cultivated with DMEM-LG supplemented with $15 \%$ fetal bovine serum, $1 \mathrm{mM}$ of $L$-glutamine, and $1 \%$ antibiotic-antimycotic solution (Gibco/Life Technologies). All incubations occurred in a 5\% $\mathrm{CO}_{2}$ atmosphere at $37^{\circ} \mathrm{C}$. Medium was replaced 3 times a week until cells reached confluence. At $80 \%$ confluence cells were harvested with a trypsin/EDTA solution ( $0.25 \%$ trypsin, 4 mM EDTA; Gibco/Life Technologies) and seeded onto new flasks.

BM-MSCs were expanded until the fifth passage and analyzed by flow cytometry to determine the expression profile of stem cell markers as defined by the International Society of Cell Therapy. All BM-MSCs samples expressed CD90, CD73, and CD105 on at least 95\% of all cells with very low (or absent) expression of CD45, CD34, CD14, and HLA-DR. Differentiation of BM-MSCs into three cell types (adipocytes, osteocytes, and chondrocytes) was successfully achieved after culture with specific media (StemPro Adipogenesis, Chondrogenesis and Osteogenesis Differentiation Kit, Gibco/Life Technologies) and confirmation after specific staining with Oil Red for adipocytes, Alcian Blue for chondrocytes, and Alizarin Red S for osteocytes.

2.2. Coculture of BM-MSCs and OA-Chondrocytes. Cocultures $(n=6)$ were performed by seeding the paired BMMSCs and OA-chondrocytes at a 1:1 cell ratio (50,000 cells each) from each donor. BM-MSCs were seeded onto the lower chamber of a 6-well plate and OA-chondrocytes onto Millicell hanging cell culture inserts $(0.4 \mu \mathrm{m}$ pore size; Millipore, Billerica, MA, USA) in $5 \mathrm{~mL}$ of DMEM-LG supplemented with $10 \% \mathrm{FBS}, 1 \mathrm{mM}$ of $L$-glutamine, and $1 \%$ antibioticantimycotic solution. Controls were monocultures of BMMSCs and OA-chondrocytes (50,000 cells each, $5 \mathrm{~mL}$ of medium). On days 3 and 6 both monocultures and cocultures were detached with trypsin-EDTA solution. Viable cells were counted using the Trypan blue exclusion technique using a Neubauer chamber. Total RNA from the cells harvested on both days 3 and 6 was extracted for quantitative reverse transcription-polymerase chain reaction (qRT-PCR) analysis and culture supernatants were stored at $-80^{\circ} \mathrm{C}$. 
2.3. Hyaluronan Measurement. Hyaluronan measurement was performed using a highly specific enzyme-linked immunosorbent assay- (ELISA-) like fluorometric method [23]. Supernatants were boiled for $30 \mathrm{~min}$ in order to inactivate all proteolytic activity. Boiled sample triplicates and hyaluronan standards (ranging from 0 to $500 \mathrm{mg} / \mathrm{L}$ ) were incubated in plates coated with biotinylated hyaluronanbinding protein, followed by a washing process, adding of europium-marked streptavidin, and an enhancement solution. Final fluorescence was measured in a fluorometer (Perkin-Elmer Life Sciences-Wallac Oy). Individual cell numbers were used to normalize the absolute amounts of hyaluronan of each sample, including when coculture was performed. In this last case we considered the sum of both cells types added in the coculture. Thus, data are presented as mean of hyaluronan concentration in $\mathrm{pg} / \mathrm{mL}$ per cell (pg/mL/cell).

2.4. Inflammatory Cytokine Analysis. The concentrations of inflammatory molecules in the culture supernatants were simultaneously evaluated using the Cytokine Beads Array Kit (Human Inflammation, IL-8, IL-1 $\beta$, IL-6, IL-10, TNF, and IL-12p70) (BD Biosciences) by flow cytometry (FACSAria, BD Biosciences, San Jose, CA) following the manufacturer's instructions and analyzed with FlowJo (TreeStar, Ashland, OR) and BD CBA software. Concentration was normalized by cell count in each culture group and the relative production of inflammatory cytokines was expressed as $\mathrm{ng} / \mathrm{mL} /$ cell.

2.5. Gene Expression Analysis. Relative quantification of mRNA expression of hyaluronan enzymes, of extracellular molecules, and of inflammatory cytokines was performed using qRT-PCR. Total RNA was extracted with TriZol (Life Technologies) and a reverse transcriptase reaction (QuantiTect Reverse Transcription Kit, QIAGEN) was performed. qRT-PCR was carried out using the ABI7500 thermocycler (Applied Biosystems, Carlsbad, CA) and the Maxima SYBR Green qPCR Master Mix (Thermo Fisher Scientific Inc., Waltham, MA) for hyaluronan enzymes and extracellular molecules, according to the manufacturer's recommendations. Primer sequences are shown in Table 1. Expression of target genes was normalized by $\beta$-actin mRNA levels. The level of expression was then calculated as $2^{-\Delta \Delta C t}$ and expressed as the mean. The results are presented as mean fold change relative to a calibration sample (Reference RNA for Real-Time qPCR, \#636690, Clontech, Mountain View, CA, USA). For coculture analysis, fold change is presented as gene expression relative to each BM-MSC or chondrocyte monoculture.

2.6. Statistical Analysis. All data analyses were performed using GraphPad Prism version 6 (GraphPad Software, Inc., La Jolla, CA). Statistically significant differences per cell in hyaluronan (pg/mL/cell) and cytokine (ng/mL/cell) concentration were evaluated using two-way ANOVA with Tukey's post hoc test. Comparison of gene expression values between two groups was performed using unpaired $t$-test or the nonparametric Mann-Whitney test and multiple comparisons
TABLE 1: Sequence of primers.

\begin{tabular}{|c|c|}
\hline Gene name & Sequence \\
\hline \multirow{2}{*}{ Beta-actin } & $5^{\prime}$-GGCACCCAGCACAATGAAG-3' \\
\hline & $5^{\prime}$-CCGATCCACACGGAGTACTTG-3' \\
\hline \multirow{2}{*}{ HAS-1 } & $5^{\prime}$-CAAGGCGCTCGGAGATTC-3' \\
\hline & $5^{\prime}$-CCAACCTTGTGTCCGAGTCA-3' \\
\hline \multirow{2}{*}{ HAS-2 } & $5^{\prime}$-CAGACAGGCTGAGGACGACTTTAT-3' \\
\hline & $5^{\prime}$-GGATACATAGAAACCTCTCACAATGC-3' \\
\hline \multirow{2}{*}{ HAS-3 } & $5^{\prime}$-GGCGATTCGGTGGACTACAT-3' \\
\hline & 5'-CGATGGTGCAGGCTGGAT-3' \\
\hline \multirow{2}{*}{ HYAL-1 } & $5^{\prime}$-GGTGAGCTGGGAAAATACAAGAA-3' \\
\hline & $5^{\prime}$-GCCCCAGTGTAGTGTCCATATACTC-3' \\
\hline \multirow{2}{*}{ HYAL-2 } & $5^{\prime}$-GGCGCAGCTGGTGTCATC-3 ${ }^{\prime}$ \\
\hline & $5^{\prime}$-CCGTGTCAGGTAATCTTTGAGGTA-3' \\
\hline \multirow{2}{*}{ HYAL-3 } & $5^{\prime}$-TGTGCAGTCCATTGGTGTGA-3' \\
\hline & 5'-AAGGTGTCCACCAGGTAGTCATG-3' \\
\hline \multirow{2}{*}{ Collagen type I } & $5^{\prime}$-CCGCCGCTTCACCTACAGC-3' \\
\hline & $5^{\prime}$-TTTGTATTCAATCACTGTCTTGCC-3' \\
\hline \multirow{2}{*}{ Collagen type II } & $5^{\prime}$-CCGAATAGCAGGTTCACGTACA-3' \\
\hline & 5'-CGATAACAGTCTTGCCCCACTT-3' \\
\hline \multirow{2}{*}{ Aggrecan } & $5^{\prime}$-TTCAGTGGCCTACCAAGTGG-3' \\
\hline & 5'-AGCCTGGGTTACAGATTCCA-3' \\
\hline \multirow{2}{*}{ Sox-9 } & 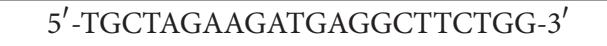 \\
\hline & 5'-GGCACTTTGTCCAGACCCA-3' \\
\hline
\end{tabular}

were performed with Kruskal-Wallis and Dunn's post hoc tests. Values are presented as mean \pm SEM of triplicate wells. In all analyses, the level of significance was considered as $P \leq 0.05$.

\section{Results}

3.1. The Number of BM-MSCs Is Decreased When Cocultured with OA-Chondrocytes. To determine effects of the cell coculture we counted the cell number of both BM-MSCs and $\mathrm{OA}$-chondrocytes remaining at the end of the coculture and compared them to the corresponding cell number when cultured alone (Figures 1(a) and 1(b)). After three days in coculture with chondrocytes, BM-MSCs count decreased $28 \%$ compared to BM-MSCs cultured alone $\left(7.6 \times 10^{4}\right.$ versus $\left.10.6 \times 10^{4}\right)$. The difference increased as time in culture progressed and after six days BM-MSCs numbers were only $53 \%$ of the cells cultured alone $\left(6.3 \times 10^{4}\right.$ versus $\left.13.5 \times 10^{4}\right)$. We observed that the number of BM-MSCs decreased after 6 days in coculture with $\mathrm{OA}$-chondrocytes in comparison to 3 days $\left(7.6 \times 10^{4}\right.$ versus $\left.6.3 \times 10^{4}\right)$, but no statistical difference was observed. The number of OA-chondrocytes cultured together with BM-MSCs, however, did not change significantly at both time points analyzed (Figure 1(b)). In spite of these changes, no significant variation in cell ratio was observed between BM-MSCs and OA-chondrocytes in coculture, after 3 days (75,920 BM-MSCs and 63,574 OA-chondrocytes, 1.2:1 cell ratio) and 6 days (65,000 BM-MSCs and 71,944 OAchondrocytes, after 3 and 6 days, resp., i.e., $0.9: 1$ cell ratio). 


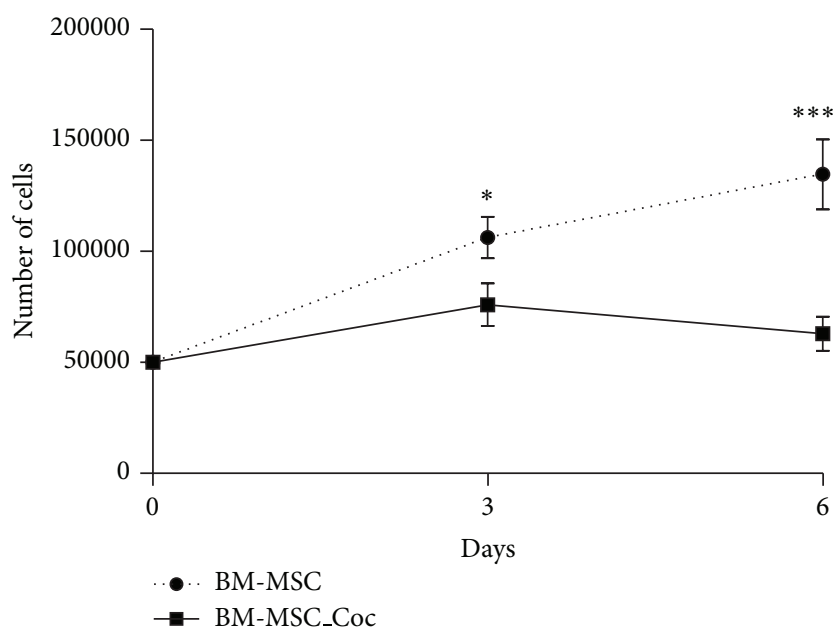

(a)

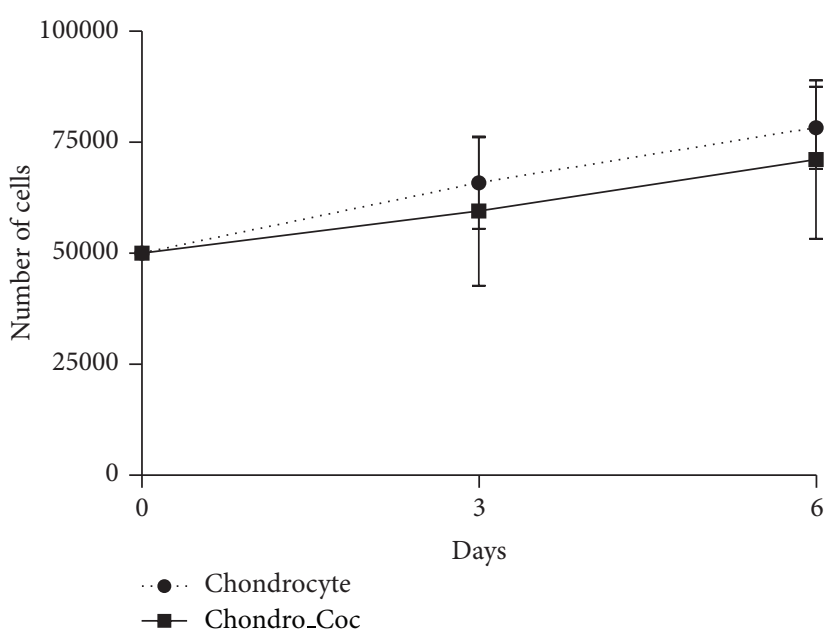

(b)

FIGURE 1: BM-MSCs decrease cell number after coculture with OA-chondrocytes. Number of cells cultivated for 3 and 6 days in monoculture ( $n=6$; bone marrow mesenchymal stem cells (BM-MSCs) and chondrocytes) or in coculture ( $n=6$; BM-MSC_Coc and Chondro_Coc). Error bars represent the SEM for the mean value. Statistical significance (two-way ANOVA) is set according to the number of asterisks, as follows: ${ }^{*} P \leq 0.05,{ }^{* * *} P \leq 0.0001$.

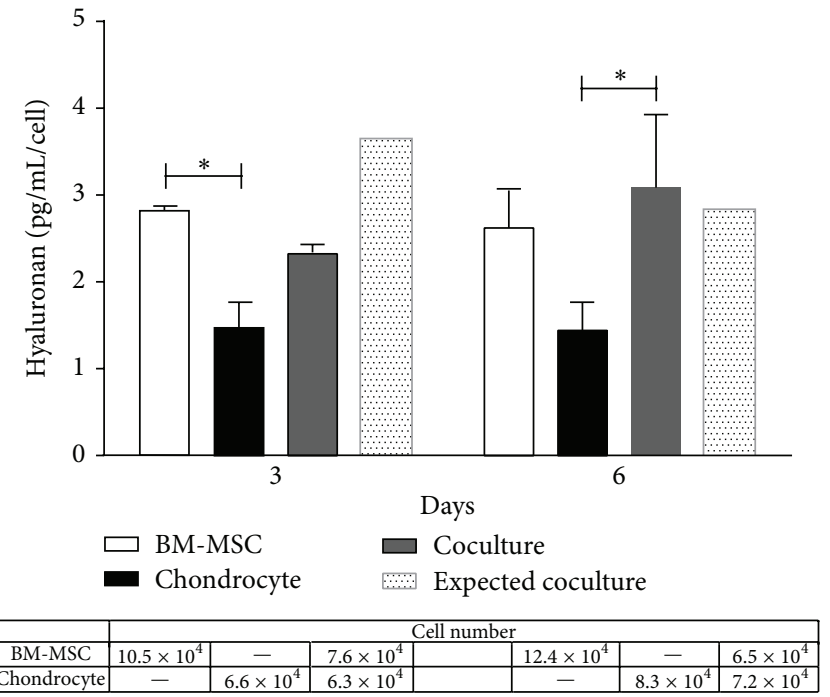

FIGURE 2: Coculture upregulates hyaluronan production. Hyaluronan concentration $(\mathrm{pg} / \mathrm{mL} / \mathrm{cell})$ after 3 and 6 days in monoculture (BM-MSCs and chondrocytes) or in coculture. Bars represent the mean and SEM; bars with gray line (expected coculture) show "expected hyaluronan production in coculture," based on production of monoculture and cell number counted. Table shows the cell number in each group. The asterisk $(*)$ indicates a significant $(P \leq 0.05)$ difference between cell culture groups based on a twoway ANOVA followed by Tukey's posttest.

3.2. BM-MSCs and OA-Chondrocyte Coculture Modulates Hyaluronan Production. To determine whether hyaluronan synthesis could be altered by coculture, we measured hyaluronan secreted by the cells in monoculture and when cocultured. Data on hyaluronan concentration obtained were normalized by cell number, in order to account for the greater number of cells in the coculture. To evaluate individual OA-chondrocyte and BM-MSC contribution in coculture, expected values were calculated based on the sum of values obtained from individual OA-chondrocyte and BMMSC (monoculture) normalized by cell number of each cell type. We anticipated that the comparison between the expected and observed values could clarify whether the cross talk between OA-chondrocytes and BM-MSCs in coculture results in changes in hyaluronan production. Our results showed that both cells were able to synthesize hyaluronan, albeit BM-MSCs produced 2-fold more hyaluronan than OAchondrocytes $(2.80 \mathrm{pg} / \mathrm{mL} /$ cell versus $1.5 \mathrm{pg} / \mathrm{mL} /$ cell, resp.) after 3 days in monoculture (Figure 2).

Hyaluronan production per cell was increased in coculture when compared with OA-chondrocytes cultivated alone (Figure 2). On a per cell basis, after 6 days in our coculture system, hyaluronan present in the supernatant was 2.15-fold higher than that from OA-chondrocytes alone (3.09 pg/mL/cell versus $1.45 \mathrm{pg} / \mathrm{mL} /$ cell; Figure 2) but was similar to the levels detected in BM-MSCs monocultures $(2.6 \mathrm{pg} / \mathrm{mL} / \mathrm{cell})$. Though, after 3 days, hyaluronan levels show intermediate values, the same is not true for values obtained after 6 days in coculture, clearly much higher. The expected values if hyaluronan production ratio was maintained after 6 days would be $2.7 \mathrm{pg} / \mathrm{mL} /$ cell $(1.3 \mathrm{pg} / \mathrm{mL} /$ cell BM-MSC $+1.4 \mathrm{pg} / \mathrm{mL} /$ cell OA-chondrocyte) in contrast to the value of $3.09 \mathrm{pg} / \mathrm{mL} /$ cell observed.

Coculture is an important experiment when assessing cell:cell interactions. In our study cells were cocultured in a Transwell system that permitted harvesting of cells at the two defined time points and showed that though present proliferation rate of BM-MSCs was significantly decreased (cell number, Figure 2). On the other hand, products are 


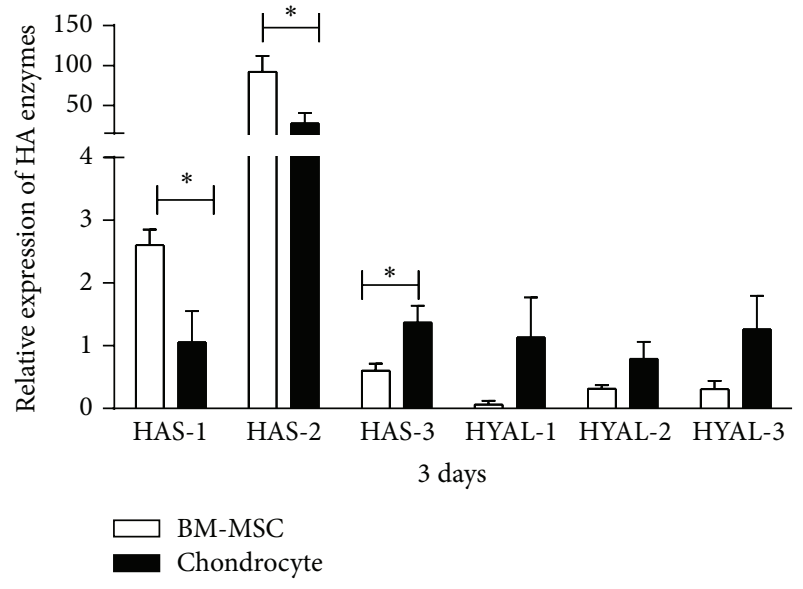

(a)

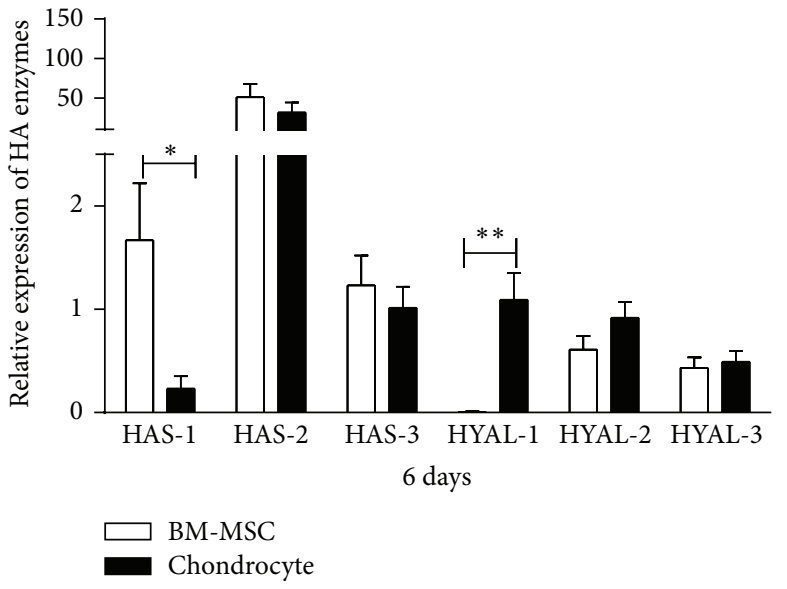

(b)

FIGURE 3: mRNA expression of hyaluronan enzymes by BM-MSCs and OA-chondrocytes. Relative mRNA expression of hyaluronan-related enzymes after 3 days (a) or 6 days (b) in monoculture. Bars represent the mean \pm SEM of hyaluronan synthase- (HAS-) 1, HAS-2, and HAS-3 and hyaluronidase- (HYAL-) 2 and HYAL-3 mRNA expression. All fold changes were calculated relative to a calibrator sample. Statistical significance based on unpaired $t$-test was set according to the number of asterisks, as follows: ${ }^{*} P \leq 0.05,{ }^{* *} P \leq 0.001$.

continuously secreted into the supernatant making this analysis more difficult. Alternatively, in BM-MSC and OAchondrocyte cultured alone, cell number increased, but no change in hyaluronan production was observed during the time points. In coculture hyaluronan concentration increased during time points, without changing the total cell number.

\subsection{Hyaluronan-Related Enzymes Are Differentially Expressed} in OA-Chondrocytes and BM-MSCs. To further clarify the contribution of each cell type to hyaluronan production, we first measured hyaluronan synthase- (HAS-) 1, HAS-2, and HAS-3 and hyaluronidases- (HYAL-) 1, HYAL-2, and HYAL3 mRNA expression in monocultures as mean fold change relative to a calibration sample. After 3 and 6 days in culture a distinct expression pattern of HAS was observed. BM-MSCs presented significantly greater HAS-1 expression than OAchondrocytes (Figures 3(a) and 3(b)); in the latter HAS-1 was practically absent after 6 days in culture. HAS-2 also varied with higher relative values exhibited by BM-MSCs. HAS3 gene expression was low in both cells and at both time points. On the other hand, mRNA expression of the three hyaluronidases was low at both time points (Figures 3(a) and 3(b)).

After 3 days in coculture relative HAS-1 mRNA expression by BM-MSCs was further increased compared to BMMSCs cultured individually (3.67-fold, Figure 4(a)). After 6 days we observed a trend towards increase of HAS1 mRNA expression by BM-MSC (Figure 4(b)). In contrast, we observed a downregulation ( 25-fold) of HYAL1 mRNA expression in BM-MSC after interaction with OA-chondrocyte at both time points (after 3 and 6 days; Figures 4(c) and 4(d)). HYAL-2 mRNA expression was also reduced after 6 days (1.5-fold) (Figure 4(d)). The expression of other enzymes was unaltered in BM-MSCs and no change in the expression of any of the enzymes was detected in the cocultured OA-chondrocytes in comparison with OAchondrocytes in monoculture (Figures 5(a)-5(d)).

\subsection{Gene Expression of Extracellular Matrix Components.} Alteration in genes related to extracellular matrix components may reflect cartilage regeneration and differentiation status. Thus, we chose to evaluate whether coculture affects the mRNA expression of type I and type II collagen, Sox-9, and aggrecan. Our findings showed that OAchondrocytes maintained the expression of chondrogenic markers throughout the experiment. No significant difference in expression of extracellular matrix genes (type I and II collagen, aggrecan) and Sox-9 was observed after 3 or 6 days of coculture system (Supplementary Figures 1(a) and 1(b) in Supplementary Material available online at http://dx.doi.org/10.1155/2015/640218).

3.5. Coculture Alters Cytokine Production. To evaluate the effects on the inflammatory microenvironment, we measured six cytokines (IL-8, IL-1 $\beta$, IL-6, IL-10, TNF, and IL-12p70) in the culture supernatants of OA-chondrocytes and BM-MSCs cocultures. Only IL- 6 and IL- 8 were present in detectable levels and there was no evidence of production of the remaining cytokines investigated. Similarly to hyaluronan synthesis, we normalized cytokine production by the cell number measured at 3 and 6 days.

As expected, OA-chondrocytes produced 8-fold greater amounts of IL- 6 than BM-MSC after 3 days $(113 \mathrm{ng} / \mathrm{mL} /$ cell versus $14 \mathrm{ng} / \mathrm{mL} /$ cell), a difference maintained at 9 -fold after 6 days $(238 \mathrm{ng} / \mathrm{mL} /$ cell versus $25 \mathrm{ng} / \mathrm{mL} /$ cell; Figure 6(a)). Similarly, OA-chondrocytes produced more IL-8 than BMMSCs, a 14 -fold increase after 3 days $(130 \mathrm{ng} / \mathrm{mL} /$ cell versus $9 \mathrm{ng} / \mathrm{mL} / \mathrm{cell}$ ) and a 21-fold increase after 6 days (107 ng/mL/cell versus $5 \mathrm{ng} / \mathrm{mL} /$ cell; Figure 6(b)). Interestingly, as a result of coculture IL- 6 secretion per cell was 


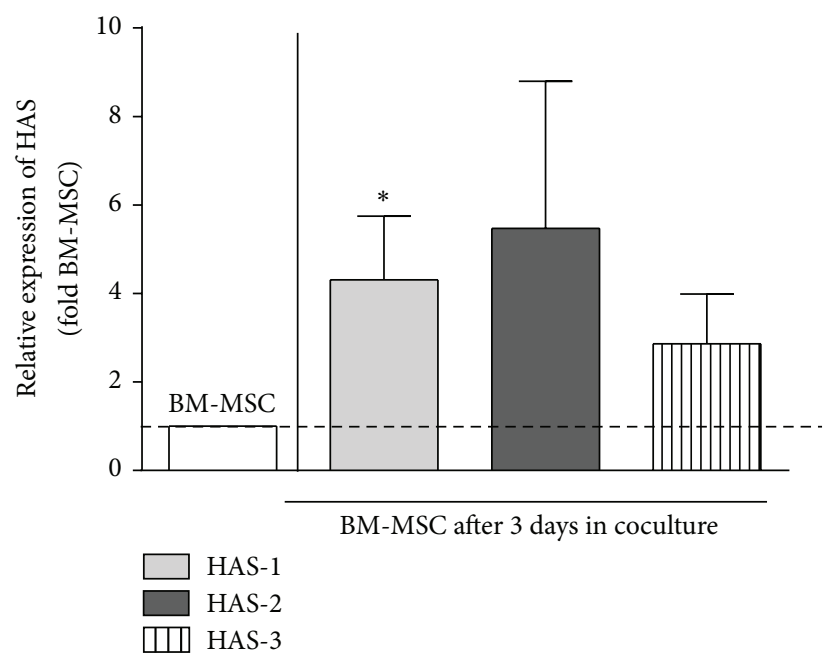

(a)

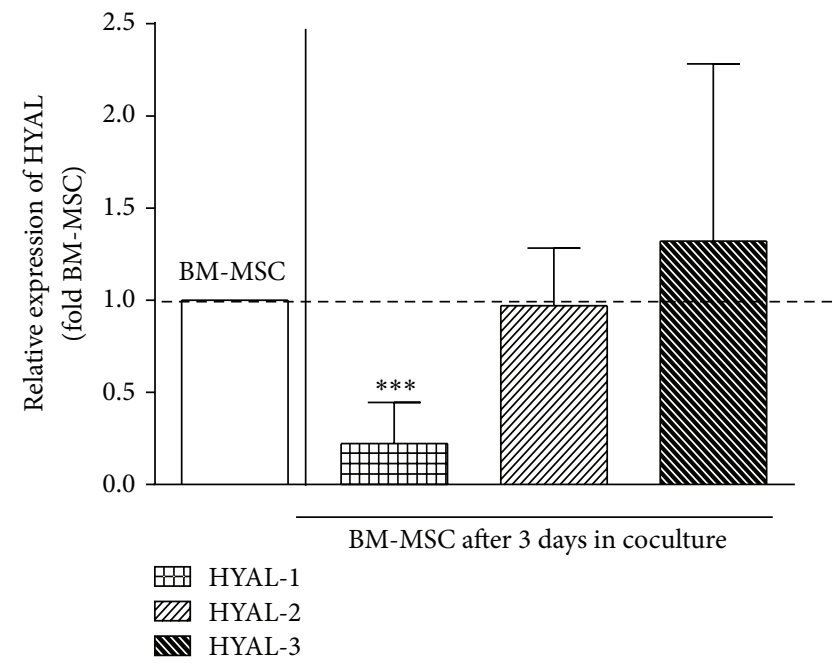

(c)

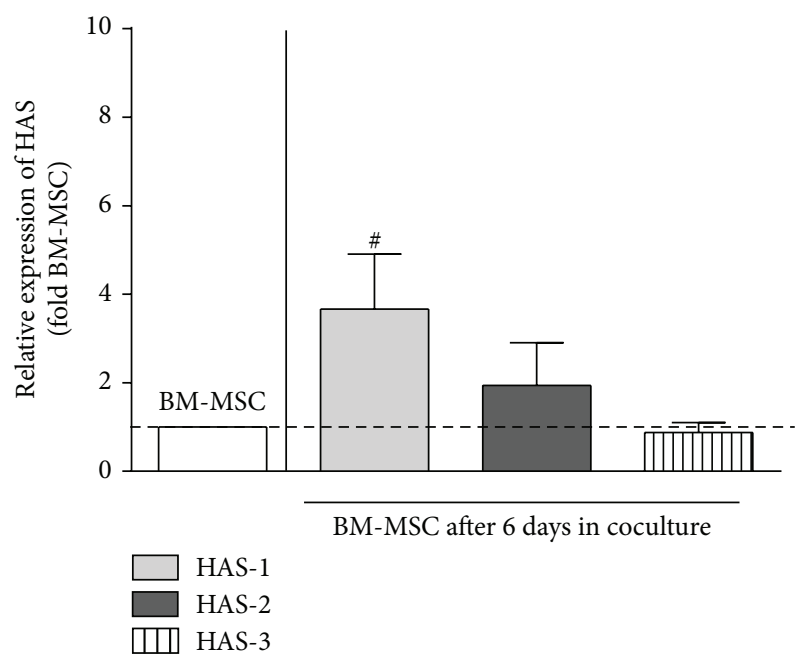

(b)

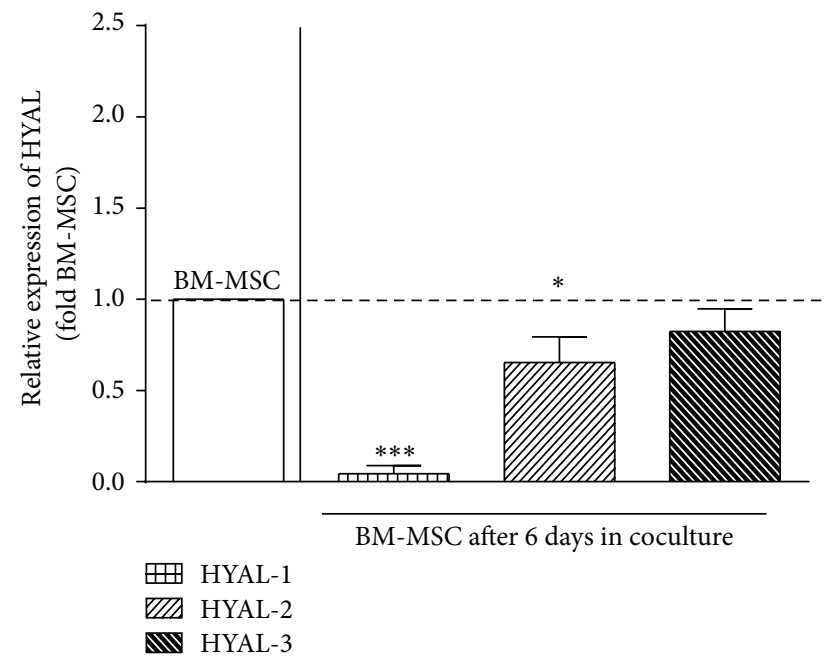

(d)

Figure 4: Hyaluronan enzyme mRNA expression in BM-MSC after coculture. mRNA expression of hyaluronan synthase- (HAS-) 1, HAS2, and HAS-3 (a-b) and hyaluronidase- (HYAL-) 1, HYAL-2, and HYAL-3 (c-d) after coculture relative to time-matched and cell-matched controls. Expression of HAS in cocultivated BM-MSC relative to BM-MSC monoculture after 3 days (a) and 6 days $(n=5)(\mathrm{b})$; expression of hyaluronidases in cocultivated BM-MSC relative to BM-MSC monoculture after 3 days (c) and 6 days (d) $(n=5)$. Bars represent the mean fold change value \pm SEM relative to BM-MSC in monoculture of hyaluronan enzymes. Statistical significance based on unpaired $t$-test was set according to the number of asterisks, as follows: ${ }^{*} P \leq 0.05,{ }^{* *} P \leq 0.001$.

of lower levels when compared to chondrocytes in monoculture $(55 \mathrm{ng} / \mathrm{mL} /$ cell versus $113 \mathrm{ng} / \mathrm{mL} /$ cell $)$ and of greater levels when compared to BM-MSCs $(55 \mathrm{ng} / \mathrm{mL} /$ cell versus $14 \mathrm{ng} / \mathrm{mL} /$ cell). This pattern was also observed after 6 days (130 ng/mL/cell versus $238 \mathrm{ng} / \mathrm{mL} /$ cell, coculture versus OAchondrocyte, and $25 \mathrm{ng} / \mathrm{mL} /$ cell BM-MSC, resp., Figure 6(a)). In contrast to the increase in hyaluronan observed, the secretion of IL- 6 by OA-chondrocytes was clearly downregulated. The expected values if secretion levels were maintained would be $249 \mathrm{ng} / \mathrm{mL} /$ cell $(12 \mathrm{ng} / \mathrm{mL} / \mathrm{BM}-\mathrm{MSC}+237 \mathrm{ng} / \mathrm{mL} / \mathrm{OA}$ chondrocyte $=249 \mathrm{ng} / \mathrm{mL} /$ cell) but were only $130 \mathrm{ng} / \mathrm{mL} /$ cell. The same occurred with IL- 8 where expected values would be $109 \mathrm{ng} / \mathrm{mL} /$ cell (i.e., $2.3 \mathrm{ng} / \mathrm{mL} / \mathrm{BM}-\mathrm{MSC}+107 \mathrm{ng} / \mathrm{mL} / \mathrm{OA}$ chondrocyte) but reached only $30 \mathrm{ng} / \mathrm{mL} /$ cell, indicating a trend for lower production.
IL-8 measured after coculture was also lower than when OA-chondrocytes were cultured individually but did not reach statistical difference after both $3(130 \mathrm{ng} / \mathrm{mL} / \mathrm{cell}$ versus $51 \mathrm{ng} / \mathrm{mL} /$ cell $)$ and 6 days $(107 \mathrm{ng} / \mathrm{mL} /$ cell versus $30 \mathrm{ng} / \mathrm{mL} /$ cell, Figure 6(b)). Although the IL-8 concentration in coculture observed $(30 \mathrm{ng} / \mathrm{mL} /$ cell $)$ was different from the expected $(109 \mathrm{ng} / \mathrm{mL} /$ cell, i.e., $2.3 \mathrm{ng} / \mathrm{mL} / \mathrm{BM}-\mathrm{MSC}+$ $107 \mathrm{ng} / \mathrm{mL} / \mathrm{OA}$-chondrocyte), we did not reach statistical difference between coculture and OA-chondrocytes.

\section{Discussion}

In the present study we sought to establish the impact of autologous BM-MSC on hyaluronan production and their effects on the secretion profile of chondrocytes from patients 


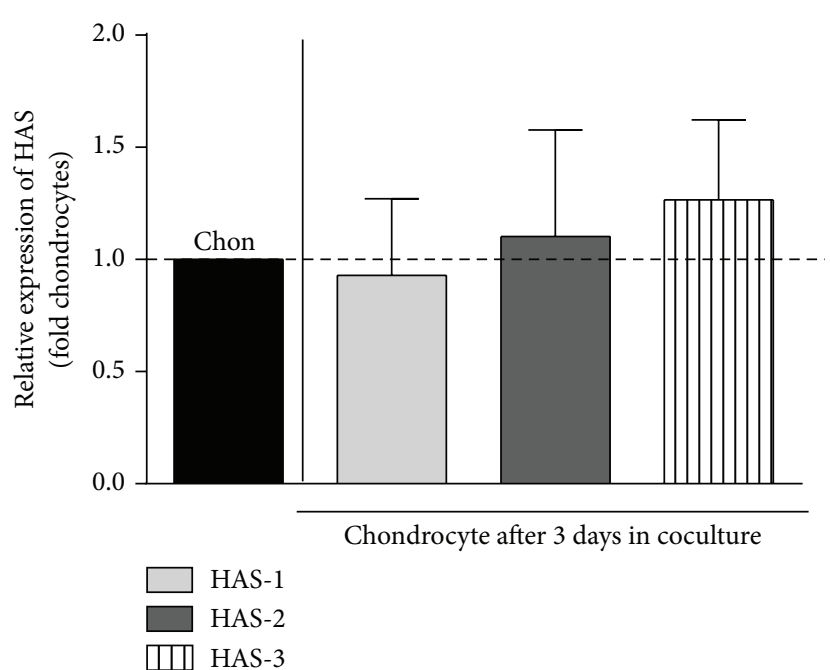

(a)

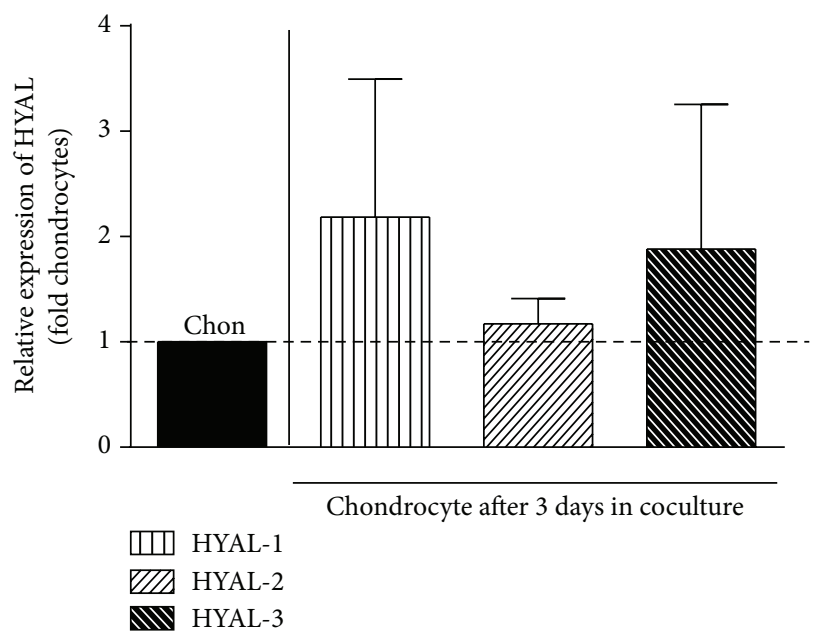

(c)

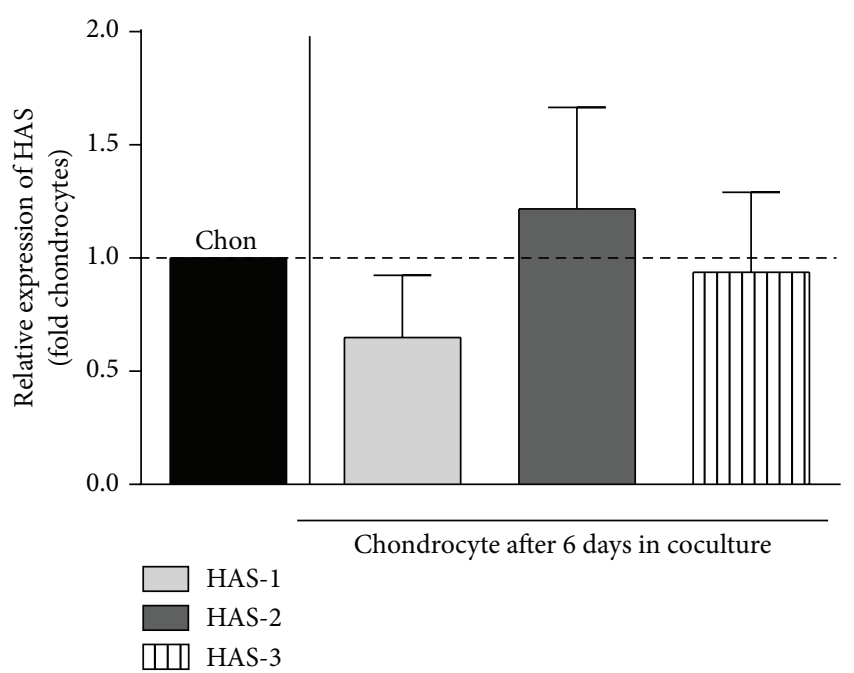

(b)

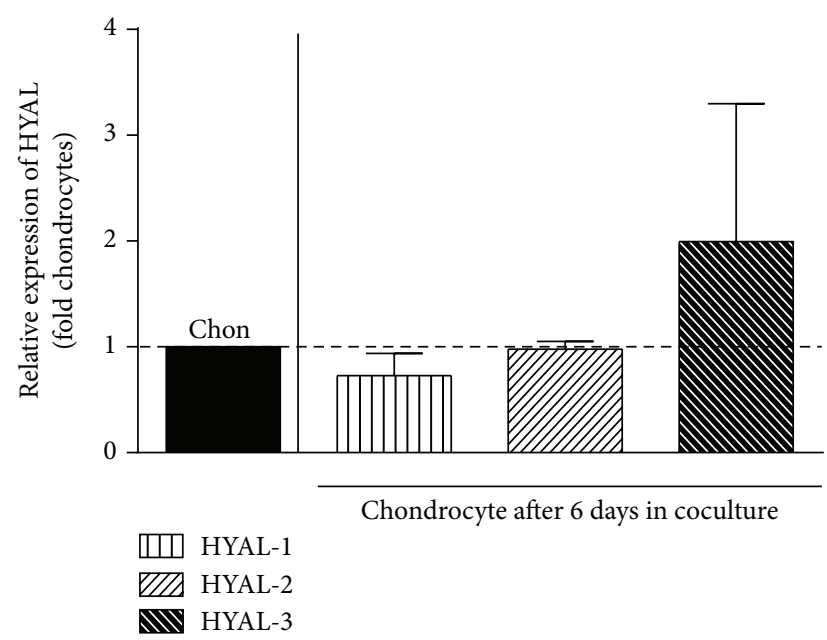

(d)

FIGURE 5: Hyaluronan enzyme mRNA expression in OA-chondrocytes after coculture. mRNA expression of hyaluronan synthase- (HAS-) 1, HAS-2, and HAS-3 (a-b) and hyaluronidase- (HYAL-) 1, HYAL-2, and HYAL-3 (c-d) after coculture relative to time-matched and cellmatched controls. Expression of HAS in cocultivated chondrocytes (Chon) relative to Chon monoculture after 3 days (a) and 6 days (b) $(n=5)$; expression of hyaluronidases in cocultivated chondrocyte relative to Chon monoculture after 3 days $(\mathrm{c})$ and 6 days $(\mathrm{d})(n=5)$. Bars represent the mean fold change value \pm SEM relative to chondrocyte in monoculture of hyaluronan enzymes. Statistical significance based on unpaired $t$-test was set according to the number of asterisks, as follows: ${ }^{*} P \leq 0.05,{ }^{* *} P \leq 0.001$.

with OA. Our coculture experiments suggest that an interaction occurs between BM-MSC and OA-chondrocytes in a Transwell system, which favors hyaluronan production. Moreover, we were able to show that BM-MSCs alone produce high amounts of hyaluronan and exhibit abundant HAS-1 mRNA expression.

Hyaluronan is a key component of the cartilage matrix and is used widely as an anti-inflammatory and antinociceptive agent in the treatment of $\mathrm{OA}$, improving joint lubrication and shock absorbance [24, 25]. Intra-articular hyaluronan injection has been employed in the management of patients with OA. The anti-inflammatory, anabolic, and chondroprotective action of hyaluronan has been increasingly evidenced, suggesting that hyaluronan helps to reduce pain and improve cartilage function [26]. Therefore, insights into mechanisms that can change hyaluronan levels in OA are relevant.

Several studies have investigated the effects of MSCs on chondrocytes [18, 27-29], but few have provided data to show that MSCs, and not only chondrocytes, might also be affected by the cell:cell interactions. Our study shows that coculture of BM-MSCs with OA-chondrocytes led to a decrease in BM-MSCs cell numbers which can be explained by reduced cell proliferation or cell death. However, cell death was not directly measured in the present study. These low BM-MSCs numbers after 3 or 6 days in coculture suggest that OA-chondrocytes are capable of altering BMMSCs behavior. Similar results have been shown in studies using coculture of BM-MSCs with chondrocyte pellets from 


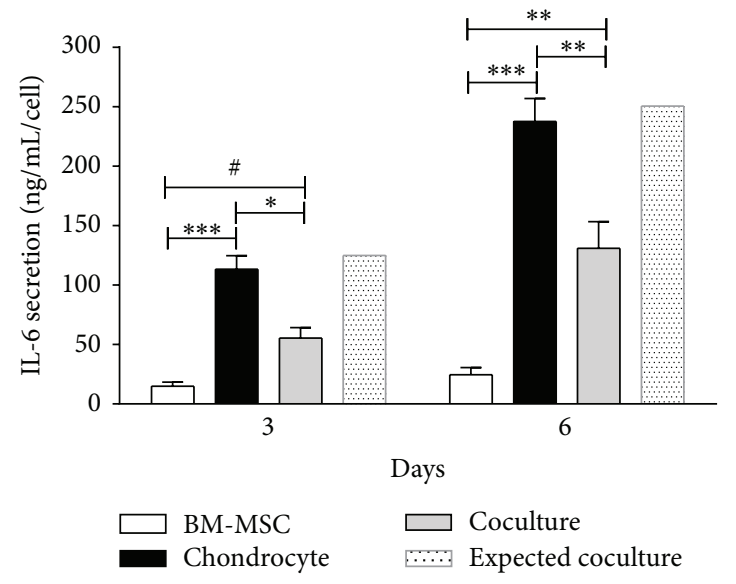

\begin{tabular}{|c|c|c|c|c|c|c|c|}
\hline & \multicolumn{7}{|c|}{ Cell number } \\
\hline BM-MSC & $10.5 \times 10^{4}$ & - & $7.6 \times 10^{4}$ & & $12.4 \times 10^{4}$ & - & $6.5 \times 10^{4}$ \\
\hline Chondrocyte & - & $6.6 \times 10^{4}$ & $6.3 \times 10^{4}$ & & - & $8.3 \times 10^{4}$ & $7.2 \times 10^{4}$ \\
\hline
\end{tabular}

(a)
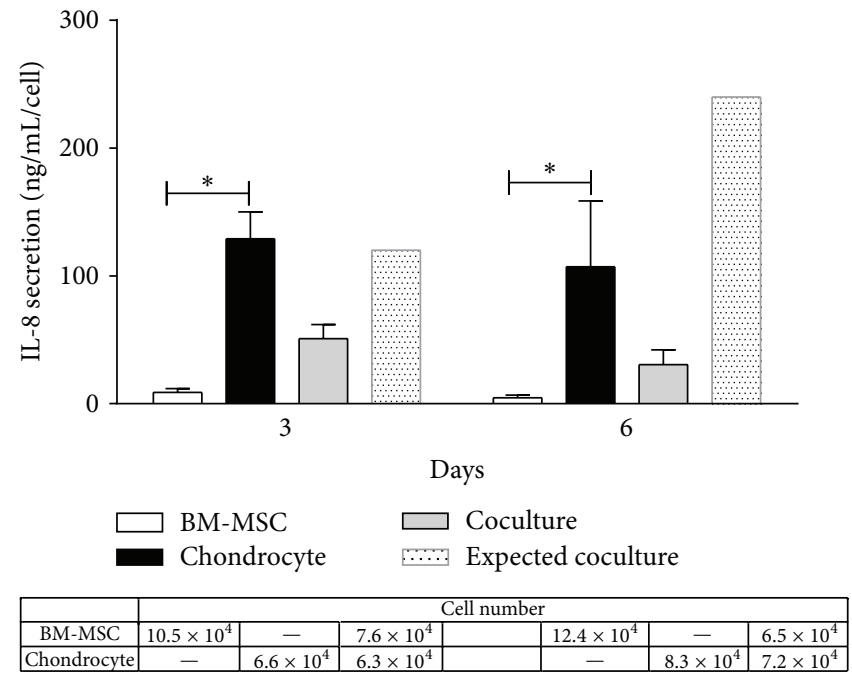

(b)

FIGURE 6: OA-chondrocytes produce higher IL-6 and IL-8 levels than BM-MSCs and cocultured cells and decrease these cytokines. Interleukin (IL) production for 3 and 6 days in monoculture $(n=5$; BM-MSCs and chondrocytes) or in coculture $(n=5)$. IL- 6 concentration (ng/mL/cell) (a). IL-8 concentration (ng/mL/cell) (b). Overall, bars represent the mean value with the SEM; bars with gray line (expected coculture) show expected ILs synthesis in coculture, based on production of monoculture and cell number counted. Table shows cell number in each group. Statistical significance based on a two-way ANOVA with Tukey's posttest was set according to the number of asterisks, as follows: ${ }^{*} P \leq 0.05$, ${ }^{* *} P \leq 0.001$, and ${ }^{* * *} P \leq 0.0001$. Tendency of statistical differences between cell culture groups was identified by \#.

different sources, during 3- to 4-week periods of culture, in which BM-MSCs numbers decreased progressively and differentiated into chondrocytes $[18,30]$. Thus, it is possible that in the present short-term cultures the trend towards differentiation into chondrocytes with a slowdown of the proliferation rate was already present and that an extended culture time would eventually favor chondrogenic marker alterations. In fact, in a previous study employing coculture with direct contact between MSCs and OA-chondrocytes, the increase in chondrogenic markers was observed later, beginning only after day 7 [31]. Nevertheless, our findings show that a short culture period is necessary and sufficient to change hyaluronan production in this microenvironment.

Hyaluronan production by MSCs has been recently described [32], but we have shown that an at least twice greater hyaluronan production occurs by BM-MSCs from the same patient than by OA-chondrocytes themselves. In addition, when BM-MSCs were cultured together with OAchondrocytes, the pattern of increased production was still maintained although at lower rates than when BM-MSCs were cultured alone. Reduction in BM-MSC cell number concomitant with no change in OA-chondrocyte number most probably affected hyaluronan production. Given that the expected and observed values of hyaluronan showed significant differences, it can be concluded that BM-MSCs contribute to hyaluronan production in our coculture system.

Thus, the present study provides evidence for a role of BM-MSCs in hyaluronan synthesis in OA. Our values for hyaluronan production were similar to the short-term (1 day) BM-MSCs monolayer cultures (range between 2.25 and $49.74 \mathrm{pg} / \mathrm{mL} /$ cell [32]) even though we cultured the cells for longer periods (6 days).
Hyaluronan enzymes HAS-1 and HAS-2 have previously been shown to be downregulated in chondrocytes collected from OA cartilage when compared to the primary chondrocytes or cartilage $[33,34]$. We measured mRNA expression levels of hyaluronan synthases to clarify which and to what extent BM-MSCs and OA-chondrocytes contribute to hyaluronan levels produced. Our data show that HAS-1, but not other isoforms, is increased in BM-MSCs when compared to OA-chondrocytes, suggesting that HAS-1 may have an important role in the hyaluronan production in our system. HAS-1 is the preponderant hyaluronan synthase present in native cartilage, which synthesized the high molecular weight hyaluronan which is found in normal cartilage [33]. The greater HAS-1 expression in BM-MSCs after coculture with OA-chondrocytes indicates that BM-MSCs might be capable of upregulating hyaluronan production in OA cartilage, though. The cocultured OA-chondrocytes exhibited unchanged expression of HASs after 3 or 6 days in culture. It is possible that 6 days is not enough time to induce this change. It is also important to note that a $3 \mathrm{D}$ culture could eventually induce more rapid changes as a result of the BMMSCs secreted factors.

Hyaluronan levels in the extracellular matrix and, ultimately, the regenerative potential in cartilage are determined not only by hyaluronan synthesis and but also by its degradation. Therefore, expression of enzymes involved in hyaluronan degradation was analyzed in OA-chondrocytes and in BM-MSCs. Among these enzymes, HYAL-1 has been described as an enzyme critical for cartilage development [8]. HYAL-1 mRNA was detected at higher levels in OAchondrocytes than in BM-MSCs cultured alone. To our knowledge, the present study is the first to show mRNA 
expression profile of HYALs in BM-MSCs in comparison with OA-chondrocytes. Our results show that HYAL-1 and HYAL-2 mRNA expression are downregulated in BM-MSCs after coculture with OA-chondrocytes, in concordance with the higher amounts of hyaluronan found in this system. Because HYAL-1 and HYAL-2 hydrolyze hyaluronan fragments of different sizes and have been suggested as the most abundant hyaluronan-degrading enzymes, these enzymes may be working together to degrade hyaluronan in OA $[10,11]$. The expression of other enzymes did not change in BM-MSCs and OA-chondrocytes after coculture. Thus, our data suggest that OA-chondrocytes modulate BM-MSCs by increasing HAS-1 and inhibiting HYAL-1 and HYAL-2 expression in order to synthesize higher molecular weight hyaluronan and, consequently, improve the local microenvironment.

The beneficial effect of hyaluronan on cartilage regeneration was demonstrated in an in vivo study using hyaluronan hydrogel combined with MSC [35]. The hyaluronan production by BM-MSCs might also have a direct antiinflammatory role. Hyaluronan injection in the knees of OA patients has been associated with decreased IL-6, but not with IL-8 levels in the synovial fluid, which correlated with clinical improvement [36]. Another study suggested that the presence of hyaluronan reduces TNF- $\alpha$ and IL- 6 concentration in coculture of OA-cartilage explants with synoviocytes [37].

Osteoarthritic cartilage is typically characterized by the presence of cytokines associated with inflammation, such as interleukin-1 beta (IL-1 $\beta$ ), IL-10, IL-6, and TNF- $\alpha$, besides proteolytic molecule MMPs. These cytokines are secreted by chondrocytes and contribute to OA development [13, 38]. Our results show that OA-chondrocytes in culture maintain secretion of high levels of inflammatory molecules even in the presence of interfering factors such as fetal calf serum. These OA-chondrocytes produced large amounts of IL- 6 and IL- 8 even though kept for long periods in culture, suggesting that they preserve an "inflammatory memory." In contrast, BM-MSCs obtained from the same individual showed low levels of IL- 6 and IL- 8 production. In fact, coculture of OA-chondrocytes with the paired BM-MSCs reduced IL6 secretion on a "per cell" basis. These observations are consistent with a report showing an anti-inflammatory effect of adipose-derived allogeneic MSC on OA-chondrocytes with a decrease of IL-6 and IL-8 production [27]. A differential production of IL- 8 was, however, not detected in our analyses.

The beneficial hyaluronan production and antiinflammatory role of BM-MSCs indicate that the cross talk with OA-chondrocytes may stimulate synthesis of other soluble molecules creating a more propitious environment for cartilage regeneration. Experimental models that permit cell contact (using OA cartilage explants) suggested that the microenvironment of $\mathrm{OA}$ cartilage does affect the chondrogenic potential of BM-MSCs [39].

The fact that in our study coculture was established without cell:cell contact opens new avenues of cell therapy using even allogeneic MSCs, which would induce short-term changes, by adding hyaluronan and blockading IL-6 and IL- 8 , to induce a more regenerative and less inflammatory microenvironment in the affected OA cartilage.

\section{Conclusion}

BM-MSCs produce hyaluronan and modulate this production in response to cross talk with OA-chondrocytes.

In conclusion, our data support the hypothesis that BMMSCs produce hyaluronan in response to OA-chondrocytes, increasing mRNA expression of HAS-1 associated with HYAL-1 downregulation and hyaluronan synthesis. The interaction promoted also an overall lower IL- 6 production. Taken together, these results indicate that BM-MSCs per se can be a potential tool for OA regenerative therapy. Our study offers insights into the mechanisms whereby treatment with BMMSCs would exert beneficial effects on the diseased cartilage as a therapeutic strategy to increase hyaluronan production and decrease inflammation locally. More importantly, our data point to a strategic role of MSCs in differentiating into more active, specialized cells and not only in remodeling chondrocytes. However, more basic and preclinical studies that consider MSC as an alternative OA treatment are needed.

\section{Conflict of Interests}

The authors declare that they have no conflict of interests.

\section{Authors' Contribution}

All authors read and approved the final paper. Eliane Antonioli, Mario Ferretti, and Anna Carla Goldberg contributed to the conception and design; Eliane Antonioli, Mario Ferretti, and Moisés Cohen contributed to collection and assembly of data; Eliane Antonioli and Helena B. Nader performed experiments and data acquisition; Eliane Antonioli, Carla A. Piccinato, and Mario Ferretti contributed to data analysis and interpretation; Eliane Antonioli, Carla A. Piccinato, Mario Ferretti, and Anna Carla Goldberg contributed to writing; Helena B. Nader and Anna Carla Goldberg contributed to editing; Mario Ferretti contributed to financial and administrative support.

\section{Acknowledgments}

This work was supported by FAPESP (Proc.: 2012/00831-7). The authors would like to thank the technical assistance of A. Mendes, M.S., from the Department of Biochemistry of the Federal University of São Paulo, for collaboration in hyaluronan measurement and Luiz Sardinha, Ph.D., from Hospital Israelita Albert Einstein, for help with flow cytometry analysis. Special thanks are due to Hospital Israelita Albert Einstein for supporting research.

\section{References}

[1] M. Maldonado and J. Nam, “The role of changes in extracellular matrix of cartilage in the presence of inflammation on the pathology of osteoarthritis," BioMed Research International, vol. 2013, Article ID 284873, 10 pages, 2013.

[2] R. F. Loeser, "Aging and osteoarthritis: the role of chondrocyte senescence and aging changes in the cartilage matrix," Osteoarthritis and Cartilage, vol. 17, no. 8, pp. 971-979, 2009. 
[3] J. Dudhia, "Aggrecan, aging and assembly in articular cartilage," Cellular and Molecular Life Sciences, vol. 62, no. 19-20, pp. 22412256, 2005.

[4] A. Aspberg, "The Different Roles of Aggrecan Interaction Domains," The Journal of Histochemistry and Cytochemistry, vol. 60, no. 12, pp. 987-996, 2012.

[5] N. Itano and K. Kimata, "Mammalian hyaluronan synthases," IUBMB Life, vol. 54, no. 4, pp. 195-199, 2002.

[6] P. H. Weigel and P. L. DeAngelis, "Hyaluronan synthases: a decade-plus of novel glycosyltransferases," Journal of Biological Chemistry, vol. 282, no. 51, pp. 36777-36781, 2007.

[7] K. S. Girish and K. Kemparaju, “The magic glue hyaluronan and its eraser hyaluronidase: a biological overview," Life Sciences, vol. 80, no. 21, pp. 1921-1943, 2007.

[8] S. B. Nicoll, O. Barak, A. B. Csóka, R. S. Bhatnagar, and R. Stern, "Hyaluronidases and CD44 undergo differential modulation during chondrogenesis," Biochemical and Biophysical Research Communications, vol. 292, no. 4, pp. 819-825, 2002.

[9] R. Stern and M. J. Jedrzejas, "Hyaluronidases: their genomics, structures, and mechanisms of action," Chemical Reviews, vol. 106, no. 3, pp. 818-839, 2006.

[10] G. Chow, C. B. Knudson, and W. Knudson, "Expression and cellular localization of human hyaluronidase-2 in articular chondrocytes and cultured cell lines," Osteoarthritis and Cartilage, vol. 14, no. 9, pp. 849-858, 2006.

[11] M. Yoshida, S. Sai, K. Marumo et al., "Expression analysis of three isoforms of hyaluronan synthase and hyaluronidase in the synovium of knees in osteoarthritis and rheumatoid arthritis by quantitative real-time reverse transcriptase polymerase chain reaction," Arthritis Research \& Therapy., vol. 6, no. 6, pp. R514R520, 2004.

[12] C. R. Flannery, C. B. Little, C. E. Hughes, and B. Caterson, "Expression and activity of articular cartilage hyaluronidases," Biochemical and Biophysical Research Communications, vol. 251, no. 3, pp. 824-829, 1998.

[13] M. Kapoor, J. Martel-Pelletier, D. Lajeunesse, J.-P. Pelletier, and H. Fahmi, "Role of proinflammatory cytokines in the pathophysiology of osteoarthritis," Nature Reviews Rheumatology, vol. 7, no. 1, pp. 33-42, 2011.

[14] F. Montoya, F. Martínez, M. García-Robles et al., "Clinical and experimental approaches to knee cartilage lesion repair and mesenchymal stem cell chondrocyte differentiation," Biological Research, vol. 46, no. 4, pp. 441-451, 2013.

[15] A. I. Caplan, "Adult mesenchymal stem cells for tissue engineering versus regenerative medicine," Journal of Cellular Physiology, vol. 213, no. 2, pp. 341-347, 2007.

[16] A. M. Dimarino, A. I. Caplan, and T. L. Bonfield, "Mesenchymal stem cells in tissue repair," Frontiers in Immunology, vol. 4, article 201, 2013.

[17] M. B. Murphy, K. Moncivais, and A. I. Caplan, "Mesenchymal stem cells: environmentally responsive therapeutics for regenerative medicine," Experimental and Molecular Medicine, vol. 45, no. 11, article e54, 2013.

[18] C. Acharya, A. Adesida, P. Zajac et al., "Enhanced chondrocyte proliferation and mesenchymal stromal cells chondrogenesis in coculture pellets mediate improved cartilage formation," Journal of Cellular Physiology, vol. 227, no. 1, pp. 88-97, 2012.

[19] J. H. Lai, G. Kajiyama, R. L. Smith, W. Maloney, and F. Yang, "Stem cells catalyze cartilage formation by neonatal articular chondrocytes in 3D biomimetic hydrogels," Scientific Reports, vol. 3, article 3553, 2013.
[20] M. A. González, E. González-Rey, L. Rico, D. Büscher, and M. Delgado, "Treatment of experimental arthritis by inducing immune tolerance with human adipose-derived mesenchymal stem cells," Arthritis and Rheumatism, vol. 60, no. 4, pp. $1006-$ 1019, 2009.

[21] J. H. Kellgren and J. S. Lawrence, "Radiological assessment of osteo-arthrosis," Annals of the Rheumatic Diseases, vol. 16, no. 4, pp. 494-502, 1957.

[22] F. García-Álvarez, E. Alegre-Aguarón, P. Desportes et al., "Chondrogenic differentiation in femoral bone marrow-derived mesenchymal cells (MSC) from elderly patients suffering osteoarthritis or femoral fracture," Archives of Gerontology and Geriatrics, vol. 52, no. 2, pp. 239-242, 2011.

[23] J. R. M. Martins, C. C. Passerotti, R. M. B. Maciel, L. O. Sampaio, C. P. Dietrich, and H. B. Nader, "Practical determination of hyaluronan by a new noncompetitive fluorescence-based assay on serum of normal and cirrhotic patients," Analytical Biochemistry, vol. 319, no. 1, pp. 65-72, 2003.

[24] L. W. Moreland, "Intra-articular hyaluronan (hyaluronic acid) and hylans for the treatment of osteoarthritis: mechanisms of action," Arthritis Research and Therapy, vol. 5, no. 2, pp. 54-67, 2003.

[25] M. Ishijima, T. Nakamura, K. Shimizu et al., "Intra-articular hyaluronic acid injection versus oral non-steroidal antiinflammatory drug for the treatment of knee osteoarthritis: a multi-center, randomized, open-label, non-inferiority trial," Arthritis Research and Therapy, vol. 16, no. 1, article R18, 2014.

[26] E. J. Strauss, J. A. Hart, M. D. Miller, R. D. Altman, and J. E. Rosen, "Hyaluronic acid viscosupplementation and osteoarthritis: current uses and future directions," The American Journal of Sports Medicine, vol. 37, no. 8, pp. 1636-1644, 2009.

[27] C. Manferdini, M. Maumus, E. Gabusi et al., "Adipose-derived mesenchymal stem cells exert antiinflammatory effects on chondrocytes and synoviocytes from osteoarthritis patients through prostaglandin E2," Arthritis and Rheumatism, vol. 65, no. 5, pp. 1271-1281, 2013.

[28] P. K. Gupta, A. K. Das, A. Chullikana, and A. S. Majumdar, "Mesenchymal stem cells for cartilage repair in osteoarthritis," Stem Cell Research and Therapy, vol. 3, no. 4, article 25, 2012.

[29] Q. Zuo, W. Cui, F. Liu, Q. Wang, Z. Chen, and W. Fan, "Cocultivated mesenchymal stem cells support chondrocytic differentiation of articular chondrocytes," International Orthopaedics, vol. 37, no. 4, pp. 747-752, 2013.

[30] L. Wu, J. C. H. Leijten, N. Georgi, J. N. Post, C. A. Van Blitterswijk, and M. Karperien, "Trophic effects of mesenchymal stem cells increase chondrocyte proliferation and matrix formation," Tissue Engineering Part A, vol. 17, no. 9-10, pp. 1425-1436, 2011.

[31] A. Aung, G. Gupta, G. Majid, and S. Varghese, "Osteoarthritic chondrocyte-secreted morphogens induce chondrogenic differentiation of human mesenchymal stem cells," Arthritis and Rheumatism, vol. 63, no. 1, pp. 148-158, 2011.

[32] C. Qu, K. Rilla, R. Tammi, M. Tammi, H. Kröger, and M. J. Lammi, "Extensive CD44-dependent hyaluronan coats on human bone marrow-derived mesenchymal stem cells produced by hyaluronan synthases HAS1, HAS2 and HAS3," The International Journal of Biochemistry and Cell Biology, vol. 48, no. 1, pp. 45-54, 2014.

[33] Y. Ono, T. Sakai, H. Hiraiwa et al., "Chondrogenic capacity and alterations in hyaluronan synthesis of cultured human osteoarthritic chondrocytes," Biochemical and Biophysical Research Communications, vol. 435, no. 4, pp. 733-739, 2013. 
[34] A. D. Recklies, C. White, L. Melching, and P. J. Roughley, "Differential regulation and expression of hyaluronan synthases in human articular chondrocytes, synovial cells and osteosarcoma cells," The Biochemical Journal, vol. 354, no. 1, pp. 17-24, 2001.

[35] J. Y. Chung, M. Song, C.-W. Ha, J.-A. Kim, C.-H. Lee, and Y.B. Park, "Comparison of articular cartilage repair with different hydrogel-human umbilical cord blood-derived mesenchymal stem cell composites in a rat model," Stem Cell Research and Therapy, vol. 5, no. 2, article 39, 2014.

[36] M. Sezgin, A. Ç. Demirel, C. Karaca et al., "Does hyaluronan affect inflammatory cytokines in knee osteoarthritis?" Rheumatology International, vol. 25, no. 4, pp. 264-269, 2005.

[37] E. A. Sundman, B. J. Cole, V. Karas et al., "The antiinflammatory and matrix restorative mechanisms of plateletrich plasma in osteoarthritis," The American Journal of Sports Medicine, vol. 42, no. 1, pp. 35-41, 2014.

[38] M. B. Goldring and M. Otero, "Inflammation in osteoarthritis," Current Opinion in Rheumatology, vol. 23, no. 5, pp. 471-478, 2011.

[39] M. Leyh, A. Seitz, L. Dürselen et al., "Osteoarthritic cartilage explants affect extracellular matrix production and composition in cocultured bone marrow-derived mesenchymal stem cells and articular chondrocytes," Stem Cell Research \& Therapy, vol. 5, no. 3, article 77, 2014. 

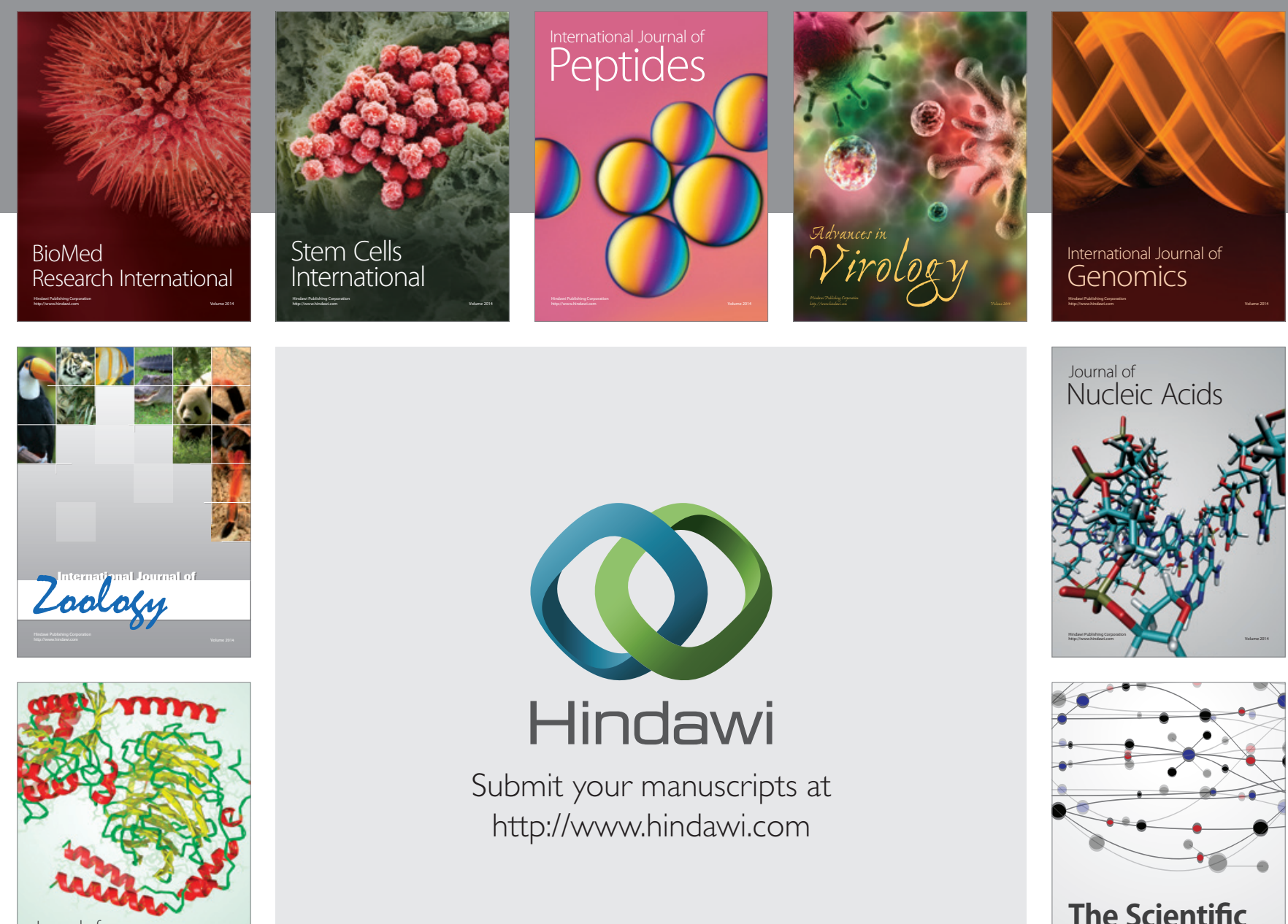

Submit your manuscripts at

http://www.hindawi.com

Journal of
Signal Transduction
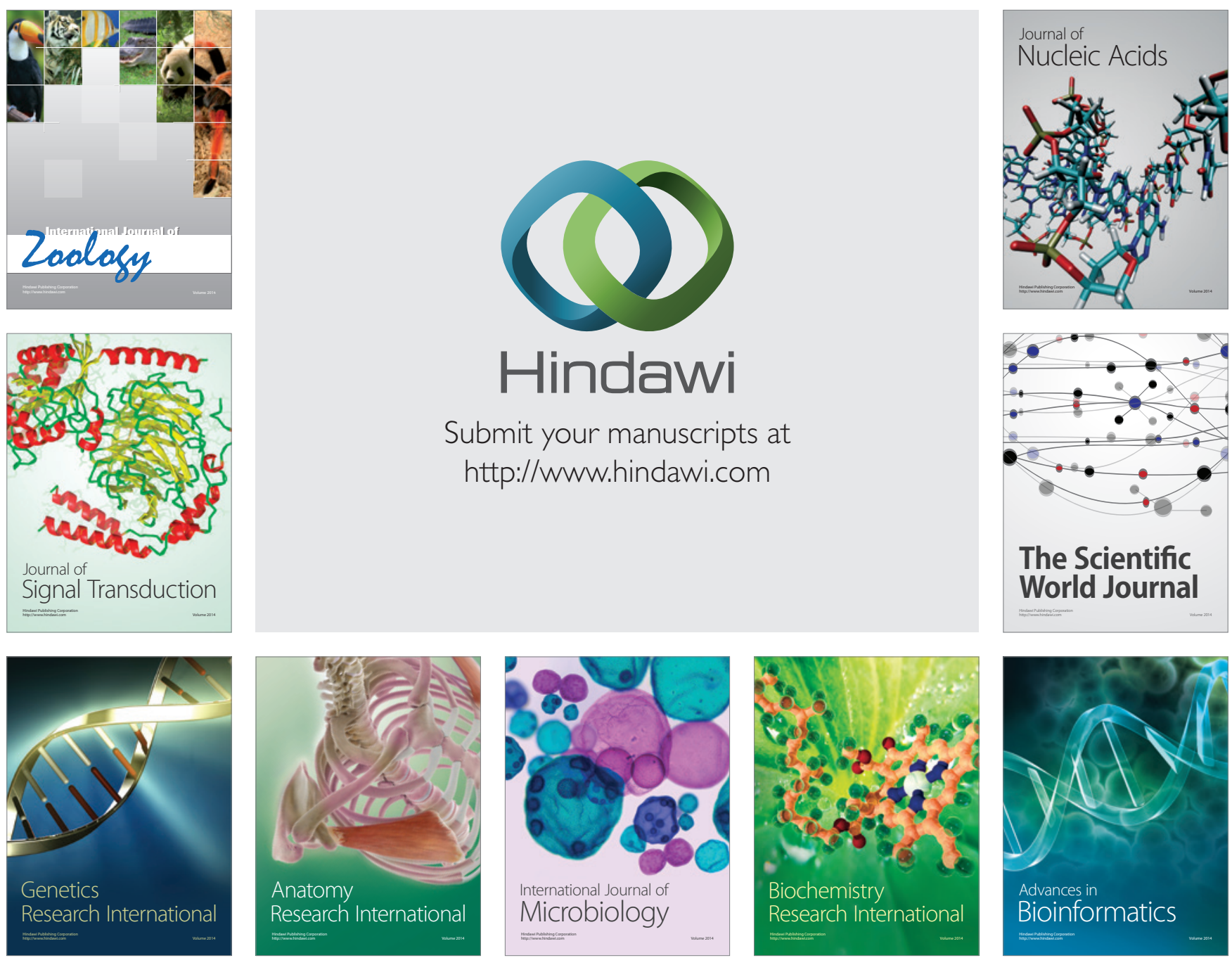

The Scientific World Journal
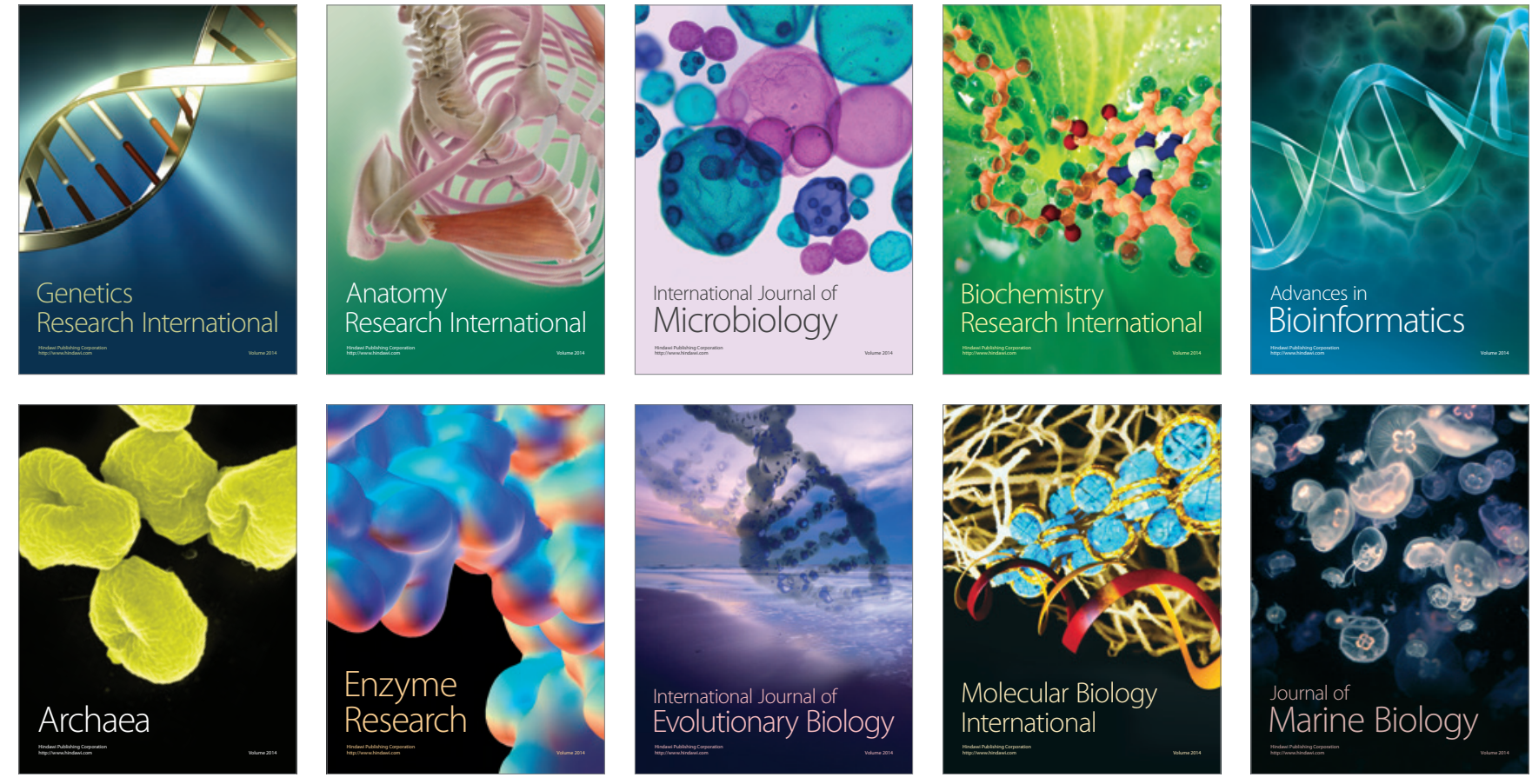